Treasury for help, and has been bailed out. At other times, when sterling has fluctuated upwards in its external value, the council has been able to relax, and even to put up a show of generosity in dealing with its dependants. The most spectacular windfall of this kind was that which fell into the council's lap towards the end of Sir Geoffrey Allen's spell as chairman in 1981. Much as Nelson turned his blind eye to an unwelcome signal, Sir Geoffrey and his then colleagues did not of fer to return their windfall from the appreciation of sterling to the Treasury but instead spent much of it on the provision of equipment in British universities. It is a fair guess that the Treasury would be more sympathetic to the problems that have now arisen if its notoriously long memory did not include a vivid recollection of that escapade.

The financial consequence for the council and for university research at large is nevertheless absurd. Faced with the need to save more than $£ 4$ million from this year's budget, the council has no choice but to raise the funds it needs by cutting back on projects that, only a few months ago, were judged to be wise expenditures of public money. The prospect for next year is on the face of things still more serious, and it is inevitable that there should be talk of the abandonment of some expensive projects or even the closure of laboratories which ostensibly exist so as to provide central services for university research. What eventually happens will depend crucially on the newly reconstituted Advisory Board for the Research Councils, which later in the year will be expected to recommend how spending on the Department of Education and Science budget should be divided among several claimants. In principle, the board could amend the provisional allocations made last November, giving the Science and Engineering Research Council some modest help. But since, with the present government's laudable devotion to the forward budgeting of public expenditure, there is unlikely to be a larger cake to cut, the edge of the council's misfortunes could be blunted only at the expense of the other research councils, which would properly complain that forward planning had been made a mockery.

If the present health of British university research is not forever to be dependent on the money markets, better ways of regulating such problems must be hammered out. British membership of organizations such as CERN at Geneva has the character of a long-term international obligation that could no more lightly be abrogated than, say, membership of the European Community. Much the same is true of the arrangements under which the research council is paying the lion's share of the cost of the observatory at Tenerife, in partnership with Spain and the Netherlands. Could not such obligations, which the research councils are not allowed to assume without the consent of the government (including the Treasury) be regarded as unshakeable international obligations whose cost should be budgeted for in the currencies in which they must be paid? Curiously enough, the Medical Research Council, formally the British subscriber to the European Molecular Biology Organization and the European Molecular Biology Laboratory, is thus protected from currency fluctuations - no doubt because it was at the outset only a reluctant subscriber. The simple but immediate need is that subscriptions to other international organizations should be dealt with the same way. Meanwhile, the research councils most directly affected should be given authority to borrow from the commercial banks.

None of this, however, will absolve the Science and Engineering Research Council from seeming the black sheep among its fellows when the science budget is reconsidered later in the year. For although the currency fluctuations that have now embarrassed the council are outside its control, the degree to which its budget is consumed by forward obligations has become uncomfortably great. The result is that rather less than half of what the council has to spend goes on the direct support of research in universities, by means of studentships, fellowships and research grants. It would now make sense to repair this imbalance not simply as a hedge against future currency fluctuations but for the sake of using resources where they can do more good. Amalgamating observatories, or closing establishments, may be prudent as well as necessary.

\section{Information revolution?}

The British Government may be wasting money in its sponsorship of computer technology.

IF somebody should invent the wheel, it is natural that others should wish to follow suit. And where wheels are concerned, imitation is likely to be swift and immediately beneficial. The development cost will be negligible, the range of applications obvious and immediate. But none of this applies to the latter-day equivalent of the wheel, the ever faster, ever cheaper, ever more commodious computer. The simplest proof of that is the efforts now being made in half a dozen major industrialized countries to "catch up", as the saying goes, with Japan in the manufacture of the next generation of computers. In the United States, both the Pentagon and a consortium of manufacturers led by Control Data are planning to spend more than they can afford on the development of very large integrated circuits. And the British Government last week said it would spend $£ 200$ million on a programme of research and development in computer technology along the lines recommended last year by the Alvey committee, commissioned by the Department of Industry to say what should be done (see Nature 24 February, p.646). But even this effort, spread as it will be over several years, is probably too little to be significant. And it may divert attention from more beneficial goals.

The trouble with modern technology, as the whole world knows, is its complexity. The development of computing engines has occupied the past 200 years (if one starts with Babbage) or the past half-century (Hartree, von Neumann and Turing). It is of course astonishing that in this quickly moving field, there is still no end in sight in the process of innovation. By contrast, the technology of civil aviation seems to have reached a plateau on which startling developments have long since given way to the modest improvements of performance and economy that, in civil aeronautical engineering as in other mature fields of engineering, now constitute progress. In the circumstances, it is not unnatural that both people and governments should be excited by the potential yet to be wrung out of computer technology, and eager to enjoy their share of it. The fact that the opportunities in computers have coincided with the remarkable growth of economic productivity in Japan is simply a coincidence - neither made the other possible.

What, in these circumstances, should governments such as the British try to do? The Alvey argument is that too little research and development is at present being carried on, and that there should be a coordinated programme towards which industry would contribute a substantial share (now fixed at $£ 150$ million). The Alvey prospectus is also comprehensive - software, hard ware, the investigation of applications and so on. The explicit goal is, by the spending of $£ 350$ million (large by most standards, tiny in this field), to enable a smallish industrial power to look its competitors in the eye, even those now embarking on almost identical programmes of research and development.

Can this make sense? It is right and proper that governments should look out for the interests of their major industries, taking care the while to obey the rules of international competition. The snag is that if every potential competitor spends money in the same kind of way, everybody will find the money wasted. In the peculiar circumstances of the international market in computers and their software, while the revoluton being wrought is still far from complete, it is already clear that the market's suppliers will become increasingly diverse in character - and specialized. The * moral, which Alvey should have seen, is that at this stage comprehensive programmes of research supported by modest funds are much less likely to succeed than more concentrated efforts towards more narrow goals. Further encouragement for successful parts of the British computer enterprise - software for example - could be more profitable. The British Government has in the past two years woken up to the invention of the computer as if it had just seen a wheel for the first time. It seems not to understand that the revolution is more complicated. 